\title{
EXPLORING THE ROLE OF THE ETHICS COMMITTEE PSYCHIATRIST
}

\author{
CHARLES C. ENGEL, Jr., M.D.
}

\section{Abstract}

Healthcare ethics committees (HEC) have emerged as institutional forums for addressing bioethical dilemmas. Psychiatrists have important roles to play on these committees. Their skills in group process assessment, mental status examination, and character assessment have diverse applications. Psychiatrists can facilitate communication within the committee and as HEC-based clinical ethics consultants. HECs must be concerned with how they arrive at ethical decisions, guarding against political influence or individual monopolization. Psychiatrists can assist these efforts as organizational consultants to HECs. The perception of psychiatrists as reflective, tolerant of ambiguity, humanizing, and approachable about ethical aspects of health care suggests they would make excellent committee leaders. Psychiatrists also have important committee roles to play as ethics educators and policy makers. More demographic data is needed to investigate psychiatrist participation on HECs. Studies of how they are perceived by their ethics committee colleagues may reveal new roles and potential pitfalls for HEC psychiatrists.

\section{Introduction}

Complex technological, medicolegal, and government forces have generated the emergence of healthcare ethics committees (HEC) over the last two decades (1)(2)(3). As these committees have evolved into multidisciplinary institutional forums (4)(5) for addressing bioethical dilemmas, so has the literature increased that addresses the roles of members from the various professions. 
Articles have appeared discussing the committee roles of critical care physicians (5)(6), nurses (7), social workers (8), clergy (9), lawyers (5), ethicists (5)(10), and lay members (5). Only recently has attention been given to the work of psychiatrists with these committees (11). The author, a psychiatrist and ethics committee member at a tertiary medical referral center, proposes that psychiatrists possess unique skills for assisting committees in the clarification and resolution of ethical dilemmas that are perhaps comparable only to those possessed by ethicists.

The purpose of this article is to address the dearth of attention to these special skills. It will explore the range of contributions of psychiatrists to HECs by discussing the complex relationship between ethics and psychiatry; comparing the qualities attributed to psychiatrists to those important for members on an HEC; reviewing the skills of psychiatrists; and, finally, examining the applicability of these skills and qualities to the HEC tasks of education, policy making, and consultation.

\section{Bioethics and Psychiatry}

To appreciate the complex issues facing the psychiatrist on an ethics committee, one must first explore the relationship between human emotions and ethical decisionmaking. Several essential issues deserve discussion here.

Medical ethics, of course, is founded on the idea that certain approaches to decisionmaking are more logical and moral than others (2). However, psychiatrists often resist the notion of a universal system of ethical reasoning. In clinical practice they must tolerate a multiplicity of belief systems and problem solving strategies to achieve an empathic understanding of their patients. Consequently, as a group psychiatrists may emphasize patient autonomy more than other physicians.

To what degree are emotional factors relevant to moral decisionmaking? E. M. Hundert (12) states that the process of establishing one's personal "ethics" is that of "striving to find the path that makes us least anxious. . . according to the scale of our conscience." $\mathrm{He}$ describes this process as unconscious and subject to intrapsychic distortions. While certain primary ethical principles are necessary to consider, how these principles are weighed is personal and inseparable from our emotions.

Another important issue for psychiatrists is pragmatic: Do emotions ever impair our ability to appropriately make decisions? 
Psychiatrists have limited powers to hospitalize patients against their will. This is due to a societal belief that emotions can so severely impair judgment and capacity to act autonomously that paternalistic interventions are warranted (2). Historically, psychiatrists have decided when this is the case.

There are important limitations as to how psychiatrists should apply their skills when patients are making treatment decisions. M. Perl and E. E. Shelp (13) maintain that hospital psychiatric consults sometimes "mask" underlying ethical questions. They describe psychiatric consultations occurring to address disagreements between patients and health care providers over medical treatment decisions. They warn against the use of psychiatrists to coerce patients into accepting treatments. Psychiatrists can improve a person's focus on relevant ethical considerations by clarifying emotional distortions but must respect the patient's right to autonomously authorize treatment.

Analysis of ethical dilemmas, therefore, involves a sorting of moral and emotional factors. It would be oversimplifying to suggest that these are the only considerations relevant to decisionmaking or even that the two are mutually exclusive; however, psychiatrists bring skills to ethical decisionmaking analogous to those of the ethicist. Ethicists approach problems by logically reasoning what is morally justifiable, placing emotional distortions in proper perspective. Psychiatrists help people gain a "realistic" slant on a decision by clarifying emotional issues.

\section{Qualities of Psychiatrists and HEC Members}

Medical training involves a socialization process that has been explored extensively (14). Rapid problem recognition and treatment response is valued, taught, and the dominant ideal in hospitals (5). People who act quickly and decisively are selected for and probably attracted to careers in medicine. The psychiatrist, by comparison, must consider problems as behaviors with several potential emotional, interpersonal, and physical explanations. A slow, deliberate process ensues involving development of rapport and empathy with the patient, consultation of hospital staff, interviews with family, and review of the medical record (15). The psychiatrist must tolerate substantial ambiguity and consciously avoid premature conclusions and interventions. The explanation for the behavior is almost always tentative and emphasizes many overlapping factors. Patience is required since premature interventions often result in 
disruption of the doctor-patient relationship and an unsatisfactory outcome. Thus, the effective psychiatrist must be contemplative, deliberate, tolerant of ambiguity, and practiced at the art of facilitating communication. Not surprisingly, the literature indicates that psychiatrists are perceived as reflective, holistic, humanizing, and approachable about moral issues (13)(16).

A comparison of the qualities attributed to effective psychiatrists versus those necessary for HEC membership reveals many similarities. Several authors have discussed attributes that lend themselves to effectiveness on an HEC (4)(5). They are: a primarily reflective and contemplative approach to problem solving; a willingness and ability to work cooperatively with people from different levels within a hierarchy; an interest in learning about ethics; a habit of thinking about right and wrong tempered with a capacity to tolerate ambiguity; and an ability to work outside a strictly scientific and technological frame of reference. The overlap between these traits and those of psychiatrists may help explain the observation of Perl and Shelp that psychiatrists are often asked to assist with bioethical problems (13).

This is not to say that psychiatrists should routinely act as hospital ethicists or even that a majority of psychiatrists would make effective HEC members. Traditional psychiatric training involves little formal preparation for resolving particular ethical dilemmas. Experience suggests that psychiatrists with more than a superficial interest in bioethics are a small minority. As noted, many resist seeing the world in terms of moral "absolutes" out of respect for cultural pluralism and individual differences. The average psychiatrist has only a dim experiential awareness of the many ethical problems faced daily in general medical practice. Other committee members may view psychiatrists as quick to voice opinions on tough decisions without a full appreciation of their consequences.

\section{Psychiatric Skills Useful to an HEC}

Psychiatrists possess special skills that have potential utility for HECs. They may be categorized as group process assessment, mental status examination, and character assessment.

\section{Group Process Assessment}

Psychiatrists are trained to consider group dynamics, the impact of group 
membership on individuals' behavior. The literature is filled with reports of the importance of facilitating communication within and between groups involved in treatment decisions as a way of resolving "ethical" dilemmas $(4)(6)(7)(17)(18)(19)$. Patients, family members, and health care providers are members of larger groups that influence their behavior. Indeed, group dynamics are constantly at work within the HEC itself, a point I shall develop shortly.

Consider the case of an elderly, widowed Hispanic woman who has end-stage multiple sclerosis and is in a persistent vegetative state, ventilator dependent, and noncommunicative. The medical team, believing further intensive care to be medically futile, approach the patient's son and two daughters regarding discontinuation of the ventilator. The son insists on continuing all treatments. The HEC is consulted.

An HEC psychiatrist is ideally suited for moderating a meeting between the family and the medical team. Such an emotionally charged situation can quickly overwhelm committee members inexperienced in group assessment. They may unwittingly respond to their own psychological needs or prior affiliations to the detriment of communication and exclusion of essential issues. While psychiatrists are not immune to these same pitfalls, they are generally skilled at promoting discussion of emotionally charged issues in a group setting. Effective psychiatrists understand cross-cultural aspects of decisionmaking and are practiced at understanding the perspectives of others. As a group, psychiatrists are more introspective than other physicians about the values of their own profession. Ethnicity, gender, socioeconomic factors, religious beliefs, the family system, interpersonal issues, grief, and individuals' previous experience with the medical system may all complicate a family'streatment decision. When psychiatrists are equipped with an understanding of the relevant ethical considerations, they can become invaluable moderators in family/medical team meetings.

\section{Mental Status Examination}

Psychiatrists are called upon to assess the mental status of patients who are making treatment decisions in order to elucidate if the patient can decide competently. Some have minimized the role of psychiatrists in evaluating competence, choosing to emphasize that competence is a legal concept determined only through legal proceedings. P. S. Appelbaum and T. Grisso (20) note, however, that assessment of patients' 
decision-making capacity is implicit whenever a physician accepts informed consent. They recommend that physicians evaluate four "psycholegal" capacities to decide which patients require legal proceedings. These capacities are: ability to communicate choices; ability to understand information relevant to the choice; ability to appreciate the situation and its consequences; and ability to rationally manipulate relevant information.

It is perhaps universally accepted that psychiatrists are useful for assessing and maximizing patients' cognitive abilities. They are well-versed in the differential diagnoses of both psychiatric and organic mental syndromes (21), and used to providing advice aimed at improving cognition in impaired patients. These same skills can be used to assess proxy decisionmakers when appropriate. Every HEC should have a psychiatrist member if only for committee guidance in this important area.

\section{Character Assessment}

A person's long-term psychological vulnerabilities and character can affect the decision-making process in frequently hidden ways.

Suppose the family from the previous case feels that further intensive care of their mother is futile and the ventilator should be discontinued to diminish her suffering. A lone dissenter on the medical team is a relatively senior medical resident assigned to the case. He believes it is wrong to discontinue life support unless a patient is declared "brain dead." The HEC is notified. To the consultant's surprise and discomfort, the resident confides in her that his mother died of multiple sclerosis when he was young. He is convinced that if his mother had lived longer, his father would have cared for him better. The HEC consultant, never faced with such a situation before, listens restlessly until the intern returns to work. The resident's past experience has resulted in false assumptions about the current patient's situation. G. Caplan has labeled this phenomenon, theme interference (22). Such false assumptions can adversely influence the decision to withdraw life-sustaining treatment, thereby undermining the patient's decision as expressed by her family.

An HEC psychiatrist is most valuable for helping the committee to address the relevant aspects of theme interference in each instance. Usually, addressing the problem as a knowledge deficit in the misinformed care provider is sufficient. A psychiatrist can provide the HEC and its consultant with strategies for tactfully educating the provider while minimizing his role as the "identified patient." At its worst, however, 
theme interference can result in a pattern of unfair biases against patients on the basis of prognosis, gender, sexual preference, or ethnic group, and may even result in patient abuse. It may be associated with severe impairments in the provider such as sociopathy, psychopathy, other personality disorders, or substance abuse. Psychiatrists are experienced at recognizing early clues of substance problems and the danger signs of severe character pathology. An HEC psychiatrist can assess the severity of the problem based on available clues and advise the committee on the need for further intervention. Theme interference can be a delicate problem, and an HEC psychiatrist is an invaluable asset to assist the committee in its nuances.

Although Caplan conceptualized theme interference as a problem in the health care provider, patients and their families may also distort situations because of past experiences. Psychiatrists can help an HEC determine the relevance of such information to various ethical dilemmas. Using their group skills, they can meet with patients and their families to address misinformation, evaluate conflicts of interest, and enhance communication. They can teach other committee members how to recognize theme interference and reduce it when it is discovered.

\section{Psychiatrists and the HEC Process}

The HEC process is the method a committee uses to accomplish its designated tasks. This is an area of controversy for many experts who question whether ethical decisions can derive from a committee process guided by custom, political power, self-interest, or even consensus (1)(23). Psychiatrists are aware that people tend to use various groups to meet specific, usually unconscious, needs. People may need to belong, dominate, be cared for, or be punished, and these needs get played out in groups such as HECs. The frequent result is that important committee tasks are overwhelmed and sometimes never adequately addressed. Given the gravity of the services that HECs provide, it is imperative to take steps to ensure that the committee's designated tasks are competently accomplished.

Psychiatrists are frequently skilled at organizational or systems consultation. These specialists use an understanding of group behavior to maximize the effectiveness of schools, businesses, hospitals, committees, and other organizations. For example, M. Weisbord's model of organizational consultation (24) involves analysis of seven aspects of 
organizational function in order to improve its productivity. The use of psychiatrists as organizational consultants to HECs is an innovative way to ensure an effective HEC process.

\section{Psychiatrists and HEC Leadership}

HEC leadership is intimately related to HEC process. Leaders, of course, do much to determine a committee's process (24). Although psychiatrists come with no particular guarantee of sound interpersonal and administrative skills, as a group they are likely to provide sound committee leadership. The image of the psychiatrist as contemplative, deliberate, tolerant of ambiguity, and practiced at the art of facilitating communication, is consistent with that of a sound HEC leader (5). The multidisciplinary composition of HECs makes it essential that leaders be comfortable and conversant with all members, not only physicians (5). An HEC leader with a good command of group process is an asset, as has been discussed. Psychiatrists' background in medicine, psychology, and the social sciences as well as their emphasis on the biopsychosocial aspects of patient care (25) prepare them to appreciate the perspectives of physicians, nurses, social workers, clergy, and other committee members.

\section{Psychiatrists and HEC Function}

HEC functions are the services committees provide. These vary with the institution, but fall into three standard categories of education, policy making, and consultation (4)(5)(6)(17)(26). Psychiatrists' specialized skills have applications in each.

\section{Education}

The earliest obligation of the HEC is to become ethically literate $(1)(4)(5)(6)$. Once this is achieved within the committee, it is ready to educate others, write policies, and perform case consultation. Psychiatrists are well-suited to develop expertise in a number of areas for the purpose of education. They can and should educate HEC members about manifestations of grief, elements of mental status relevant to patient competence, group dynamics, organizational consultation, theme interference, facilitating communication, and involuntary treatment. Certainly, this list is far from all inclusive. 


\section{Policy Making}

HECs are increasingly asked to consider institutional policies on sensitive issues (1)(4)(5)(6)(26). Policies on informed consent, do-notresuscitate orders, and withdrawal of life-sustaining treatment would benefit from psychiatric input regarding assessment of patients' competence. Psychiatrists might help with policies on assessment of proxy decisionmakers. Such an evaluation is analogous to assessing patients' competence (2). Finally, involuntary administration of psychopharmacologic agents, advance directives regarding psychiatric treatment, and euthanasia are areas of increasing controversy. Institutional policies on these issues merit attention from an HEC psychiatrist.

\section{Case Consultation}

Perhaps psychiatrists are of greatest use to HECs as clinical ethics case consultants. As mentioned, inadequate communication is ubiquitous in ethical dilemmas arising in hospitals $(5)(7)(8)(14)(17)(18)(19)$.

Emotions, past experience, and moral factors are often inseparable. Usually, it is unrealistic to expect the consultee to differentiate between psychiatric and ethical problems and make appropriate decisions about whom they should consult. Great potential exists for HEC psychiatrists to assist in this area.

Psychiatric consultations in the face of life and death treatment decisions can dramatically escalate defensiveness in patients and their families. They may fear the psychiatrist will declare them "crazy" and deprive them of their right to authorize treatment. They may feel criticized for their treatment choice, as if the consulting doctor is implying that "only an insane person could choose that treatment" (13). A psychiatrist representing the HEC can perform the appropriate evaluation without the accompanying stigma or implicit coercion of psychiatric consultation (13).

This is, of course, not to suggest that a psychiatric consultation would be inappropriate if emotional distress is present. It is important to ensure that the ethics consultant honor appropriate boundaries. When formal psychiatric treatment is indicated, the HEC psychiatrist should recommend psychiatric consultation rather than initiate psychiatric treatment in the role of ethics consultant. 


\section{Conclusion}

It is useful to speculate on ways that psychiatrists can be effective ethics committee members. The question remains, however, as to how well psychiatrists are represented on healthcare ethics committees. What services are HEC psychiatrists providing for their colleagues and institutions? Do HECs often utilize organizational consultants? How often are such consultants psychiatrists? [The author is currently organizing a survey study of ethics committees to investigate these and other questions.]

Studies of how HEC psychiatrists are perceived by their ethics committee colleagues might elucidate potential pitfalls for psychiatrists and perhaps identify new roles. Clearly, more research is needed to clarify the role of psychiatrists on HECs.

[The views expressed in this article are those of the author and do not reflect the official policy or position of the Department of the Army, the Department of Defense, or the U.S. Government]

\section{ACKNOWLEDGEMENT}

The author wishes to thank Angela L. Engel, M.A., for reviewing, commenting on, and assisting with the preparation of the manuscript. 


\section{REFERENCES}

1. McCormick RA. Ethics committees: Promise or peril? Law, Medicine \& Health Care. 1984; 12:150-55.

2. Beauchamp TL, and Childress JF. Principles of biomedical ethics, (3rd ed.). New York, NY: Oxford University Press; 1984.

3. President's Commission for the Study of Ethical Problems in Medicine and Biomedical and Behavioral Research. Deciding to forego lifesustaining treatment. Washington, D.C.: U.S. Government Printing Office; 1983.

4. Bayley C, Cranford RE. Ethics committees: What we have leamed. In: Friedman E, ed. Making choices: Ethics issues for health care professionals. Chicago, II: American Hospital Publishing Company; 1986:193-99.

5. Friedman E. Making choices: Ethics issues for health care professionals. Chicago, IL: American Hospital Publishing Company; 1986.

6. Cranford RE, Jackson DL. Neurologists and the hospital ethics committee. Seminars in Neurology. 1984; 4:15-22.

7. Murphy P. The role of the nurse on hospital ethics committees. Nursing Clinics of North America. 1989; 24:551-56.

8. Furlong RM. The social worker's role on the institutional ethics committee. Social Work and Health Care. 1986; 11:93-100.

9. Eyer RC. Clergy's role on medical ethics committees. Journal of Pastoral Care. 1985; 34:208-12.

10. Freedman B. One philosopher's experience on an ethics committee. Hastings Center Report. 1981; 11:20-22.

11. Engel CC. Psychiatrists and the general hospital ethics committee. General Hospital Psychiatry. 1992; 14:29-35.

12. Hundert EM. A model for ethical problem solving in medicine, with practical applications. American Journal of Psychiatry. 1987; 144:839-46.

13. Perl M, Shelp EE. Psychiatric consultation masking moral dilemmas in medicine. New England Journal of Medicine. 1982; 307:618-21.

14. Knight JA. Medical student: Doctor in the making. New York, NY: Appleton-Century-Crofts; 1973.

15. Hackett TP. Beginnings: Consultation psychiatry in a general hospital. In: Hackett TP, Cassem NH, eds. Massachusetts General Hospital handbook of general hospital psychiatry, (2nd ed.). Littleton, MA: PSG Publishing, Inc.; 1987.

16. Krakowski AJ. Liaison psychiatry: A service for averting dehumanization of medicine. Psychotherapy and Psychosomatics. 1979; 32:164-69.

17. Editorial: Who's for bioethics committees? Lancet 1986; 1:1016.

18. Purtilo RB. Ethics consultations in the hospital. New England Journal 
of Medicine. 1984; 311:983-86.

19. Cassem NH. Consultation to continue or stop treatment measures in irreversible illness. Advances in Psychosomatic Medicine. 1980; 10:119-31.

20. Appelbaum PS, Grisso T. Assessing patients' capacities to consent to treatment. New England Journal of Medicine. 1988; 319:1635-38.

21. Lipowski ZJ. Delirium (acute confusional states). Journal of the American Medical Association. 1987; 258:1789-92.

22. Caplan G. The theory and practice of mental health consultation. New York, NY: Basic Books, Inc:; 1970.

23. Lo B. Behind closed doors: Promises and pitfalls of ethics committees. New England Journal of Medicine. 1987; 317:46-50.

24. Weisbord M. Organizational diagnosis: Six places to look for trouble with or without a theory. Group and Organizational Studies. 1976; 1:430.

25. Engel GL. The need for a new medical model: A challenge for biomedicine. Science. 1977; 196:129-36.

26. Madden WA, Reeder J, Cragun W, et al. Evolution of military ethics committees. Military Medicine. 1987; 152:613-16. 